Journal of Advanced Research in Fluid Mechanics and Thermal Sciences

\title{
Numerical Study of Fluid Flow and Heat Transfer in a Backward Facing Step with Three Adiabatic Circular Cylinder
}

\author{
Muhammad Asmail Eleiwi ${ }^{1,}{ }^{*}$, Tahseen Ahmad Tahseen ${ }^{2}$, Ayad Fouad Hameed ${ }^{2}$ \\ Mechanical Engineering Department, College of Engineering, Tikrit University, Iraq \\ Mechanical Engineering Department, College of Engineering, University of Kirkuk, Iraq
}

\section{ARTICLE INFO}

\section{Article history:}

Received 15 October 2019

Received in revised form 15 March 2020

Accepted 19 March 2020

Available online 8 June 2020

\section{Keywords:}

Backward facing step; adiabatic three cylinders; forced convection; drag force

\section{ABSTRACT}

In this study, the analysis of the heat transfer enhancement and laminar fluid flow characteristics of three non- rotating adiabatic cylinders in the backward facing step geometry is numerically performed. The effects of Reynolds number, heat fluxes, and longitudinal distance between two consecutive cylinders on the heat transfer characteristics are studied for backward facing step flow. Five Reynolds number are studies $(\operatorname{Re}=50,100,150,200,250)$ and three heat fluxes on the lower wall of the channel are $\left(q^{\prime \prime}=250,500,750 \mathrm{~W} / \mathrm{m}^{2}\right)$, the longitudinal distance are $(2 \mathrm{H}, 3 \mathrm{H}, 4 \mathrm{H})$, where $(\mathrm{H}=10 \mathrm{~mm})$ which represent the cylinder diameter. The governing equations are discretized and solved using the finite volume method over a control volume by ANSYS Fluent software. The results show the heat transfer is increased in the channel. The reattachment distance decreased when using cylinders. The heat transfer enhancement increases from (6\%) to (13\%) if the Reynolds number change from (50) to (250) when heat flux increases (67\%). A good agreement is found when comparing the present results with literature.

Copyright $@ 2020$ PENERBIT AKADEMIA BARU - All rights reserved

\section{Introduction}

The study of heat transfer and fluid flow separation, reattachment and internal flow in backward facing step is important in many engineering applications such as the flow around buildings, aircraft wings, cooling of turbine blades, cooling of energy system equipment, cooling of nuclear reactors, HVAC systems, heat exchangers, space heating, and combustion chambers and any other engineering applications involving of sudden expansion flow. Due to vast engineering applications, the study of backward or forward-facing step fluid flow and heat transfer is conducted by many researchers [17]. It is concluded that the effect of Reynolds number on the heat transfer behind the step is obvious from increasing the Nusselt number on specific locations (mainly the bottom wall behind the step).

\footnotetext{
* Corresponding author.

E-mail address: muham76@tu.edu.iq (Muhammad Asmail Eleiwi)
} 
The main goal, for the studies done on the flow regime behind backward step, is to enhance the heat transfer in this area. The enhancement technique achieved by modifying the flow regime structure by using nanofluid or ferrofluid instead of pure fluid [8-14]. It is found that the enhancement in heat transfer is increased when using nanofluid and ferrofluid. Also, Pulsating flow is numerically studied [15-17]. The effect of pulsating flow is obvious in low pulsation frequency (5$50 \mathrm{~Hz}$ ). Placing an obstacle object with different shape in front of the fluid flow is also suggested [1827], using different types of an obstacle objects (circular cylinder, square, triangular, and trapezoidal blockage, or different types of vertical baffle on upper or lower walls) will alter the fluid flow inside the channel behind the step. This altering in fluid flow regime increase the heat transfer in all cases. Change the geometrical configuration of the backward step is also assumed $[28,29]$, the pressure losses increase with increasing step angle and step height. The effect of media is investigated by Sayehvand et al., [30], where three cylinders in staggered arrangement immersed in a channel filled with porous media. It is found that the losses in pressure is increase when using porous media in compares with empty channel, but the heat transfer is higher in former. The effect of rotating single cylinder on the heat transfer and fluid flow is studied numerically by Selimefendigil and Hakan [10] and Anguraj and Palraj [31], it is found that the direction of rotation of the cylinder will affect the fluid flow in the wake behind the cylinder. Also, the rotation changes the distribution of the local Nusselt number especially at low Reynolds number.

Based on the literature review, in spite of the vast studies have done on the flow inside backward facing step before, there is no previous results to the best knowledge of the authors are available on the problem of enhancement heat transfer in backward facing step using an adiabatic three circular cylinder for the laminar range. Therefore, the objective of this study is to investigate the effect of using three adiabatic circular non- rotating cylinders arranged in an isosceles right-angled triangle (parallel to the flow direction) on heat transfer in the backward facing step channel. The effect of various pertinent parameters such as Reynolds number, cylinders location, and heat flax on the bottom wall behind step will be examined.

\section{Problem Description and Mathematical Model}

The physical domain of the flow system for the backward facing step with three adiabatic nonrotating circular cylinders is shown in Figure $1(\mathrm{a})$. The diameter of the cylinders is $(\mathrm{H})$, all other dimensions are given as a function of $(\mathrm{H})$, where $(\mathrm{H}=10 \mathrm{~mm})$. The height of the step, inlet height, and upstream distance from the inlet plane to the step edge are $(2 \mathrm{H})$, while the non - dimensional downstream distance between the step edge to the exit plane is $(30 \mathrm{H})$. It is well known that a very poor heat transfer characteristics found in the region near the step because the flow separation and recirculation [28], so, to enhance the flow and thermal characteristics, three adiabatic circular cylinders are placed behind the step. They arranged in an isosceles right-angled triangle (height of the triangle is parallel to the flow direction) with three different horizontal locations within the channel as shown in Figure 1(b). In all cases, the distance from the step edge to the first cylinder is kept at $(2 \mathrm{H})$. The streamwise distance between cylinders is $(2 \mathrm{H})$ in case $1,(3 \mathrm{H})$ in case 2 , and $(4 \mathrm{H})$ in case 3. 


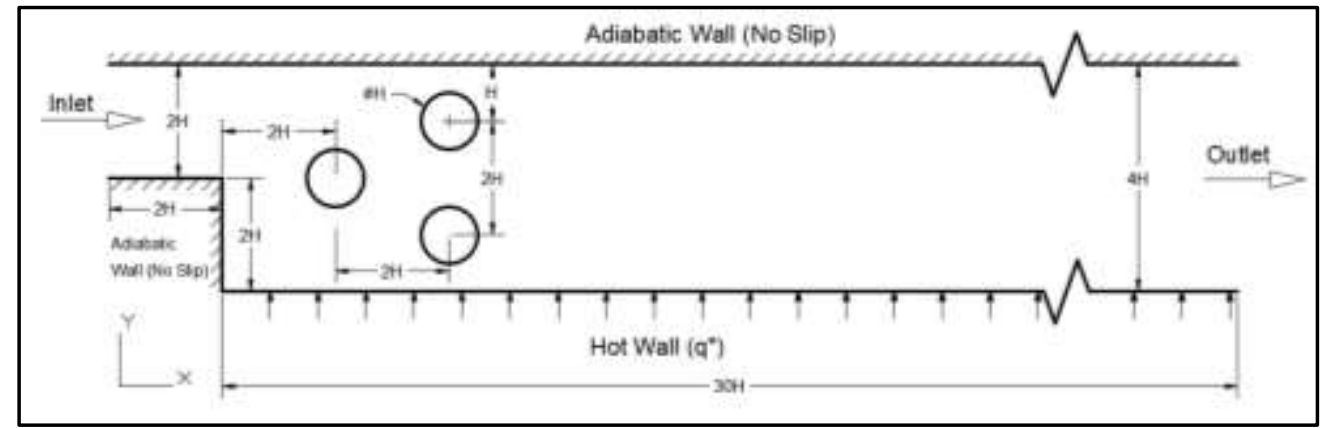

(a)

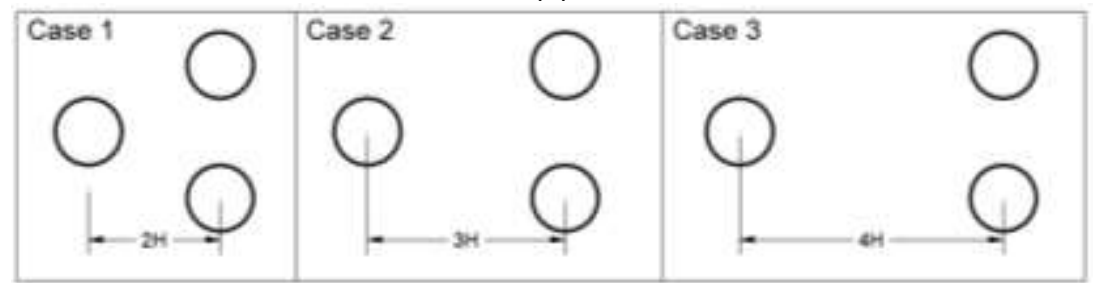

(b)

Fig. 1. Schematic diagram of backward facing step (a) the physical domain, (b) three cases for the location of the cylinders

The geometry of the backward step with the named selected in the computational solution with corresponding boundary conditions are illustrated in Figure 2 and Table 1, respectively.

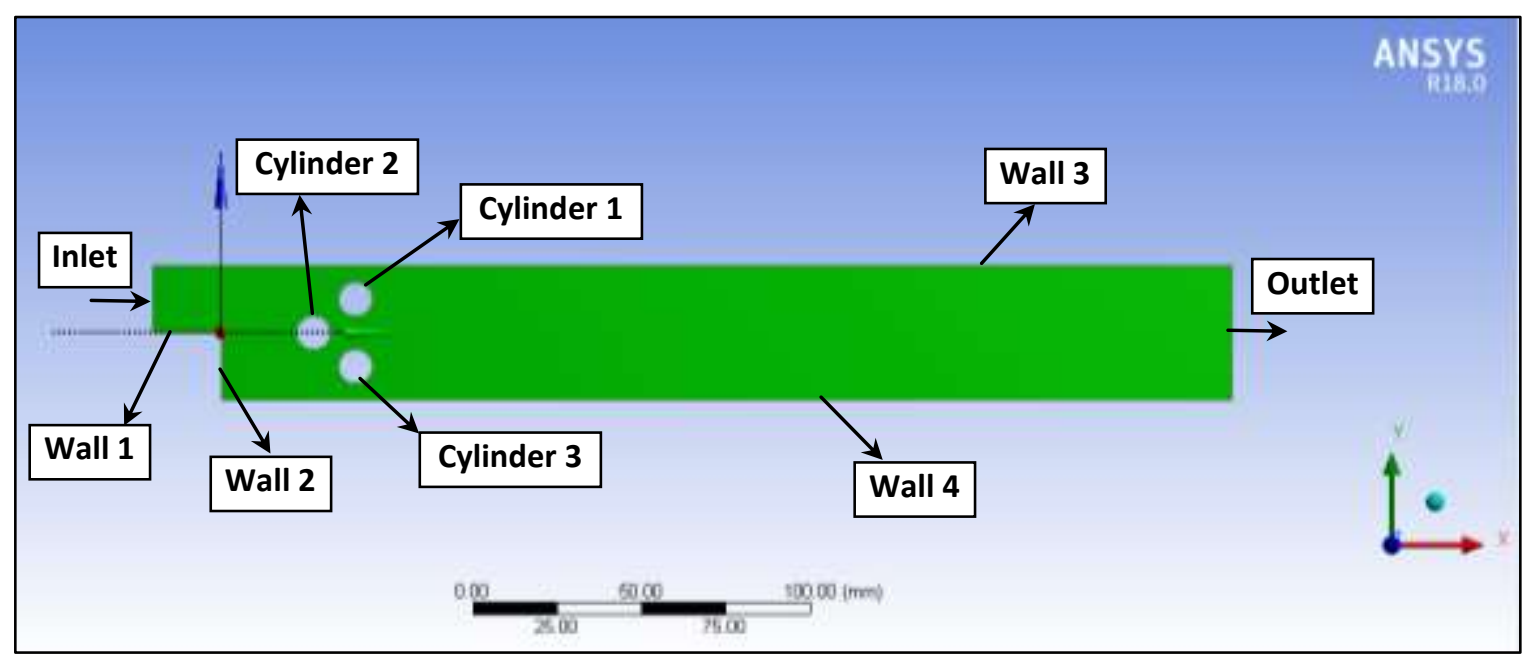

Fig. 2. Schematic description of physical domain with boundary conditions

\section{Table 1}

The boundary conditions

\begin{tabular}{llll}
\hline Named Selection & Type of Boundary Condition & Unit & Value \\
\hline Inlet & Velocity & $\mathrm{m} / \mathrm{s}$ & $0.04,0.08,0.12,0.16,0.2$ \\
Outlet & Gauge pressure & $\mathrm{Pa}$ & 0 \\
Wall 1, Wall 2, Wall 3 & Heat Flux & $\mathrm{W} / \mathrm{m}^{2}$ & 0 \\
Wall 4 & Heat Flux & $\mathrm{W} / \mathrm{m}^{2}$ & $250,500,750$ (at each inlet velocity) \\
Cylinder 1, Cylinder 2, & Heat Flux & $\mathrm{W} / \mathrm{m}^{2}$ & 0 \\
Cylinder 3 & & \\
\hline
\end{tabular}

As shown in Table 1, based on the uniform inlet velocity and the channel inlet dimension, the values of Reynolds number are $(50,100,150,200$, and 250). The downstream bottom surface of the 
backward facing step (Wall 4 in Figure 2) is exposed to a uniform heat flux ( $\left.q^{\prime \prime}\right)$, the values of the heat flux are $\left(250,500\right.$, and $\left.750 \mathrm{~W} / \mathrm{m}^{2}\right)$, while the other walls of the channel are assumed to be adiabatic with no slip conditions. The surface of the cylinders is assumed to be adiabatic also. Working fluid is air with a Prandtl number ( $\mathrm{Pr}=0.71)$. The assumptions considered in the work are as follows:

i. Flow is assumed to be steady.

ii. Two-dimensional flow.

iii. The working fluid is Newtonian.

iv. Incompressible fluid flow.

v. Laminar flow regime with no heat transfer by radiation.

Based on previous assumptions, the governing equations including the continuity, momentum and energy equations can be described in the dimensional form as follows $[17,19,21]$ :

$\frac{\partial u}{\partial x}+\frac{\partial v}{\partial y}=0$

$u \frac{\partial u}{\partial x}+v \frac{\partial u}{\partial y}=-\frac{1}{\rho} \frac{\partial p}{\partial x}+v\left(\frac{\partial^{2} u}{\partial x^{2}}+\frac{\partial^{2} u}{\partial y^{2}}\right)$

$u \frac{\partial v}{\partial x}+v \frac{\partial v}{\partial y}=-\frac{1}{\rho} \frac{\partial p}{\partial y}+v\left(\frac{\partial^{2} v}{\partial x^{2}}+\frac{\partial^{2} v}{\partial y^{2}}\right)$

$u \frac{\partial \theta}{\partial x}+v \frac{\partial \theta}{\partial y}=\alpha\left(\frac{\partial^{2} T}{\partial x^{2}}+\frac{\partial^{2} T}{\partial y^{2}}\right)$

where $(\mathrm{a})$ is the thermal diffusivity of air and given as $\left(\alpha=\frac{k}{\rho C_{p}}\right)$. Reynolds number (Re) is computed based on inlet channel height $(2 \mathrm{H})$ as follows:

$R e=\frac{u_{o}(2 H)}{v}$

The boundary conditions for the present problem in dimensionless form can be expressed as:

i. At the channel inlet: $u=$ unidirectional, $v=0$ and $T$ 回 $=300 \mathrm{~K}$.

ii. At the bottom wall, downstream of the step, temperature is changed with heat flux.

iii. At the channel exit, fully developed flow assumption is used in the $\mathrm{x}$ - direction: $\frac{\partial u}{\partial x}=\frac{\partial v}{\partial x}=$ $\frac{\partial T}{\partial x}=0$

iv. On the channel walls (except the downstream of the step) and all solid surfaces, adiabatic wall with no-slip boundary conditions are assumed: $u=0$, $\mathrm{v}=0$ and $\frac{\partial T}{\partial n}=0$, where $(\mathrm{n})$ represent normal direction.

Now, the local Nusselt number is defined as:

$N u_{X}=\frac{h_{X}(2 H)}{k}=-\left(\frac{\partial T}{\partial n}\right)$

where $\left(h_{X}\right)$ represent the local heat transfer coefficient and $(\mathrm{k})$ denote the thermal conductivity of the working fluid (air). After integrating the local Nusselt number along the bottom wall downstream the step, averaged Nusselt number is obtained as follows [19,21]: 
$N u_{\text {avg }}=\frac{1}{L} \int_{0}^{L} N u_{x} d x$

where $(L)$ is the length of the bottom surface.

The drag force is the summation of the pressure and viscous forces on the cylinder in the horizontal direction, it given by the following equation $[19,20]$ :

$F_{D}=\int_{0}^{2 \pi}(p)(\cos \theta) r d \theta+\int_{0}^{2 \pi}\left(\tau_{w}\right)(\sin \theta) r d \theta$

Finally, the drag coefficient is expressed as:

$C_{D}=\frac{2 F_{D}}{\rho u_{o}^{2} D}=\frac{2 \int_{0}^{2 \pi}(p)(\cos \theta) r d \theta}{D}+\frac{(2 / R e) \int_{0}^{2 \pi}\left(\partial u_{t} / \partial n\right)(\sin \theta) r d \theta}{D}$

where $\left(\partial u_{t} / \partial n\right)$ denotes the gradient of the tangential velocity in the direction normal to the cylinder surface.

Eq. (1)-(4) along with the boundary conditions are solved with ANSYS Fluent [30,31] (a powerful and flexible general-purpose computational fluid dynamics software package used to model flow, turbulence, heat transfer, and reactions for industrial applications). The governing equations are discretized using the finite volume method (provided by ANSYS Fluent software) over a control volume, the convective terms in the momentum and energy equations are solved using second order upwind scheme and coupled scheme is used for pressure- velocity coupling. The presto discretization is used for pressure calculation. The system of algebraic equations is solved with Gauss- Seidel point by point iterative method.

\section{Numerical Model}

\subsection{Grid Generation}

Figure 3 shows the computational grid structure adopted for solving the problem. The grid is generated using ANSYS FLUENT software, the grid is non- uniform near the cylinders, and become uniform everywhere else. The computational domain is divided into (305930) elements. The mesh is finer near the cylinder walls to capture the high gradient in the thermal and hydrodynamic boundary layer.

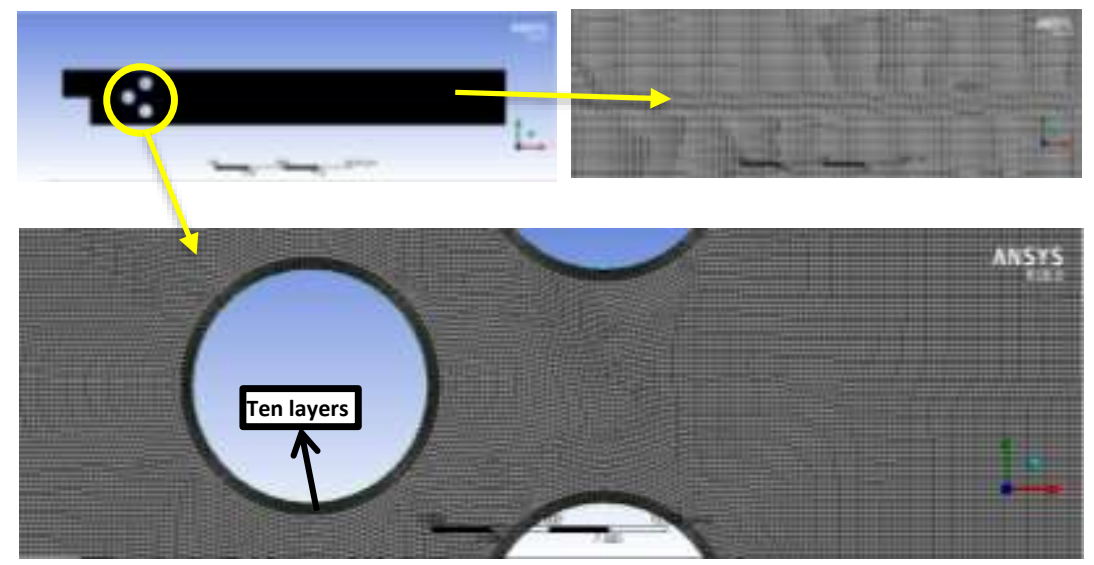

Fig. 3. Grid structure for backward step with three cylinders 


\subsection{Grid Refinement Test}

A grid independence test was done to investigate the effect of number of cells on the results at $(\operatorname{Re}=50),\left(q^{\prime \prime}=1000 \mathrm{~W} / \mathrm{m}^{2}\right)$, and for case 1 . Four different computational grids were used for that purpose, the number of cells or elements for each case are $(G 1=137158, G 2=196894, G 3=272822$ and G4 $=305930$ ) respectively. The results have been shown in Table 2. The percentage difference in the value of average Surface heat transfer coefficient at bottom wall is not exceeding (1\%).

Table 2

The result of grid independence test

\begin{tabular}{lll}
\hline Case & Number of Elements & $h_{\text {avg }}\left(\mathrm{W} / \mathrm{m}^{2} . \mathrm{K}\right)$ \\
\hline G1 & 137158 & 1.522 \\
G2 & 196894 & 1.528 \\
G3 & 277822 & 1.5225 \\
G4 & 305930 & 1.5226 \\
\hline
\end{tabular}

\subsection{Model Validation}

The model used in this work is validate with the numerical result of Kumar et al., [21]. Their study focused on heat transfer enhancement of backward- facing step laminar flows in horizontal channel by using single adiabatic circular cylinder. The flow regime is assumed steady, two- dimensional, and forced convection heat transfer. Figure 4 shows the result of the validation with the reference from Jue et al., [19], the result done for the location of the single cylinder in respect to the channel height $(y c=1)$. A good agreement is achieved as shown in the figure.

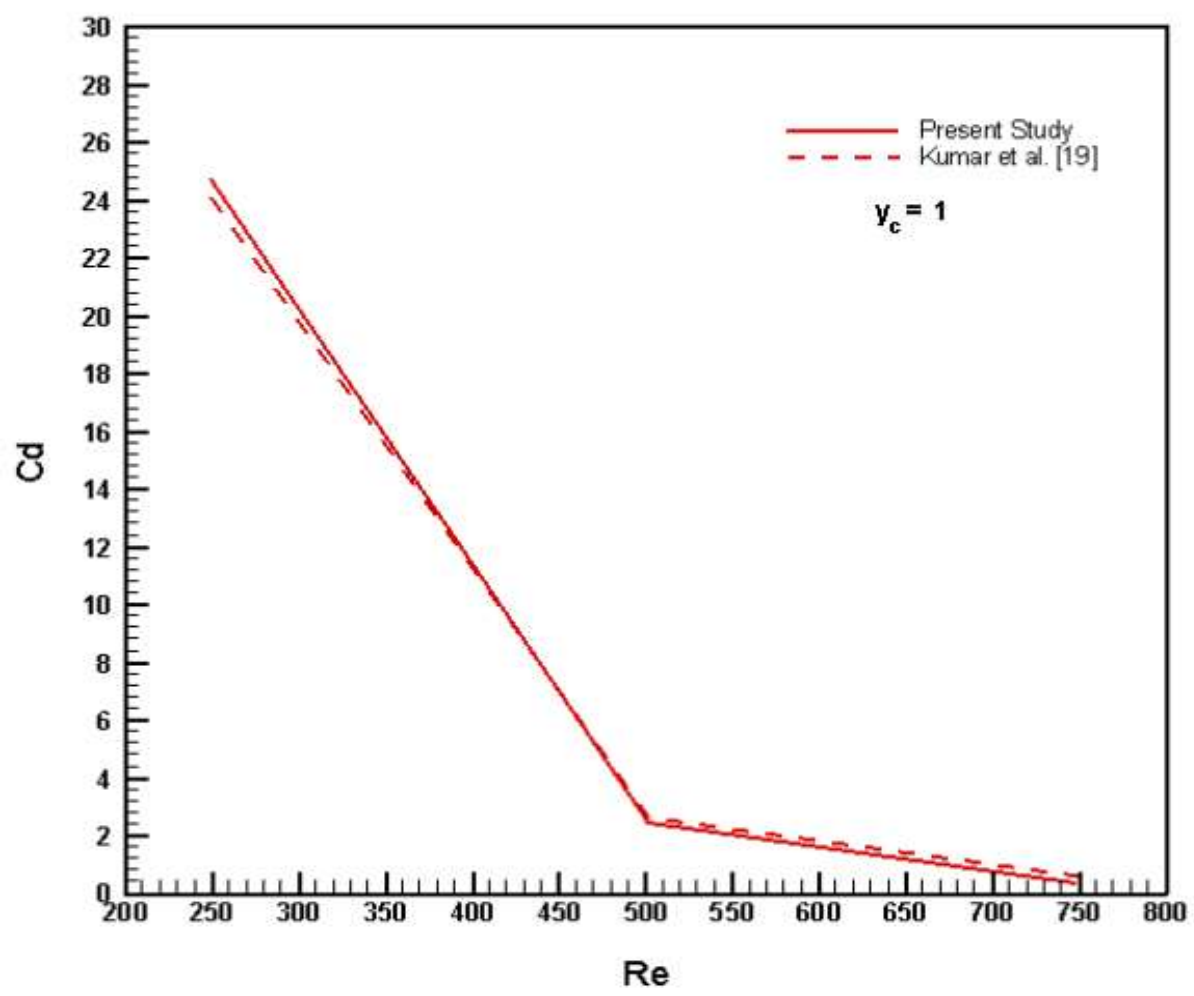

Fig. 4. Comparison of $\mathrm{Cd}$ of the present study with result of Jue et al., [19] 


\section{Results and Discussion}

The purpose of this study is to investigate the effects of three adiabatic circular cylinders on the heat transfer and fluid flow characteristics in a backward facing step. The main parameters that effect the fluid flow and heat transfer in the domain are Reynolds number, step height, distance between the step to the channel output, distance from inlet to the step, shape and number of obstacles found in the channel, and distance from the step to the location of the obstacle. In the present study, expansion ratio is (2), distance from the step to the 1st cylinder is $(2 \mathrm{H})$ (half of step height), distance from inlet to step is $(2 \mathrm{H})$, and the distance between the step to the output is $(30 \mathrm{H})$. The Reynold numbers are $(50,100,150,200$ and 250$)$, the heat fluxes are $\left(250,500\right.$ and $\left.750 \mathrm{~W} / \mathrm{m}^{2}\right)$. The distance between the cylinders are $(2 \mathrm{H}, 3 \mathrm{H}$ and $4 \mathrm{H})$.

The study of the flow field in the channel is done for various Reynolds number $(50,100,150,200$, and 250$)$ and for various heat flux $\left(250,500\right.$ and $\left.750 \mathrm{~W} / \mathrm{m}^{2}\right)$. Figure 5 shows the contour of velocity distribution, pressure and temperature around the cylinders at $(\operatorname{Re}=50$ and 250$)$ and $\left(q^{\prime \prime}=750 \mathrm{~W} / \mathrm{m}^{2}\right)$ for case 1 (distance between 1st and 2nd column of cylinders is $2 \mathrm{H}$ ), the reason of showing only two Reynolds number and one heat flux is due to lack of space. The effect of adding cylinders to the flow behind the step is obvious from the figure, the reattachment distance of the flow separation behind the step is reduced due to the presence of the cylinder because the flow will separate in the vicinity of the cylinders. The flow is accelerated near the cylinders (especially after the cylinder 1 and cylinder 2), also, a small recirculation zone produced behind the cylinders.

The recirculation zone alters the flow (also thermal boundary layer) in the direction away from the step. Previous behavior will be repeated for other Reynolds number but in scaled value. The thermal boundary layer is thinner for higher Reynolds number.

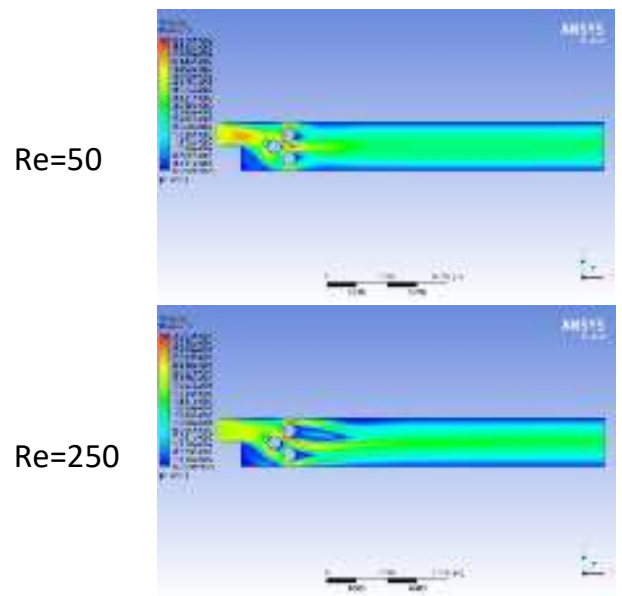

(a)

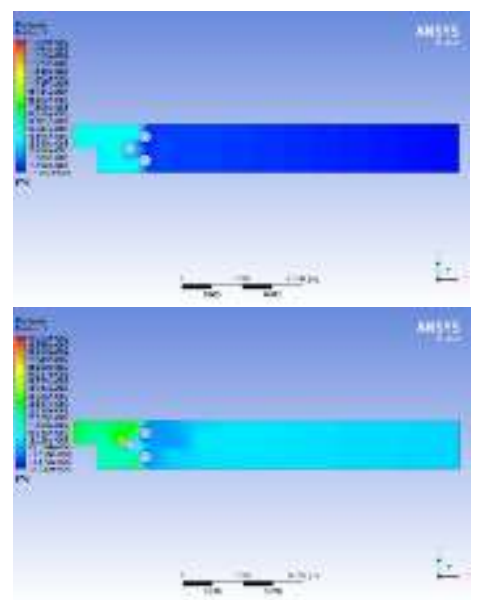

(b)

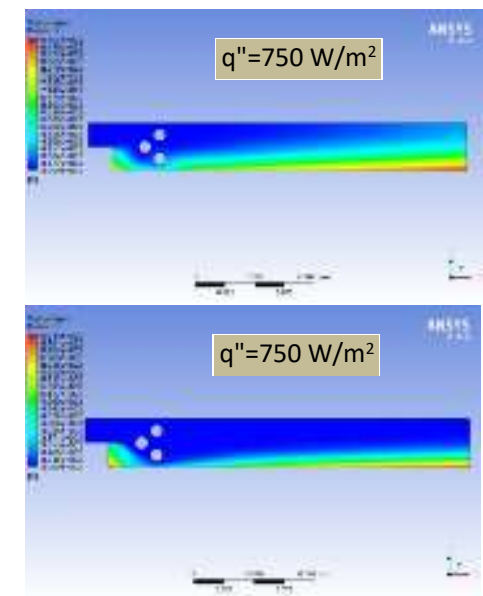

(c)

Fig. 5. Counters of (a) velocity (b) pressure and (c) temperature at selected Reynolds number and heat flux for case 1

The distance between the cylinders were changed as shown in Figure $1(\mathrm{~b})$ from $(2 \mathrm{H})$ to $(3 \mathrm{H}$ and $4 \mathrm{H}$ ), a selected result is shown in Figure 6 and Figure 7 below for the velocity, pressure, and temperature around the cylinders for new locations. 


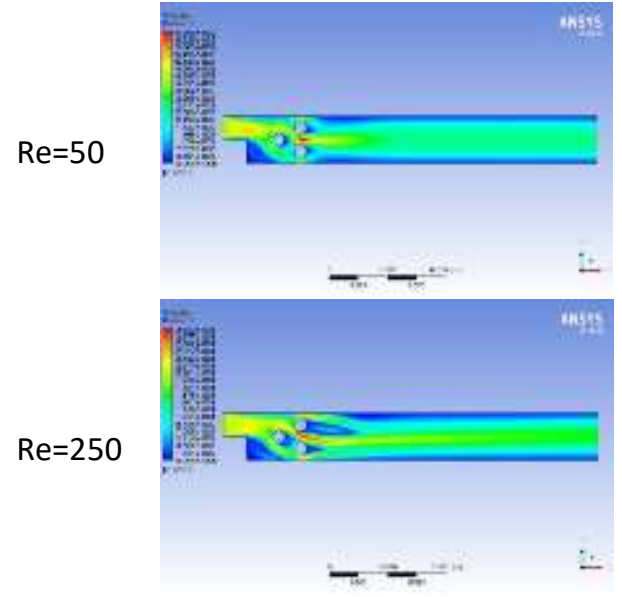

(a)

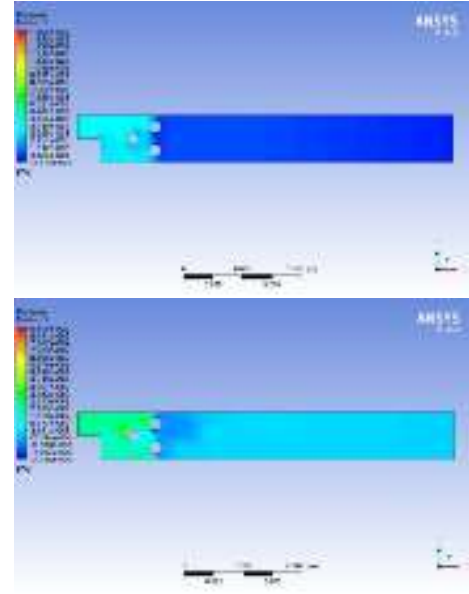

(b)

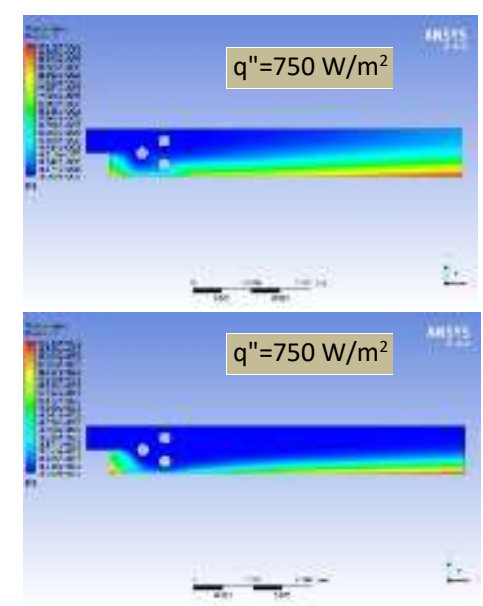

(c)

Fig. 6. Counters of (a) velocity (b) pressure and (c) temperature at selected Reynolds number and heat flux for case 2

$\operatorname{Re}=50$

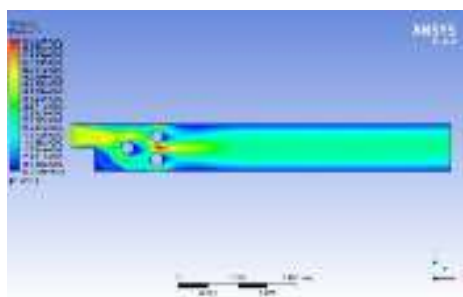

$\operatorname{Re}=250$

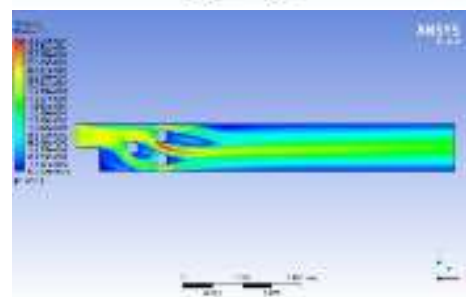

(a)

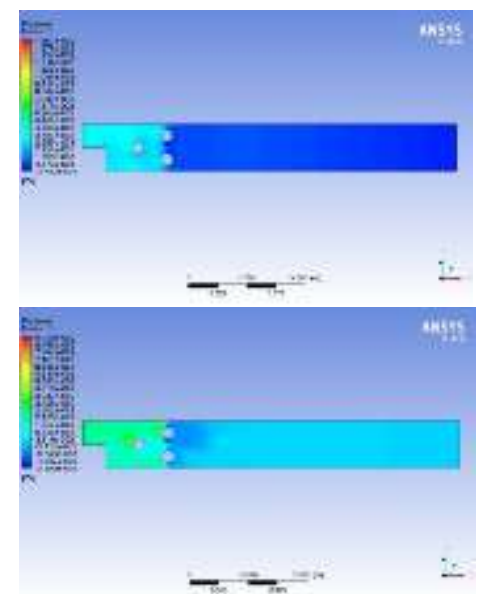

(b)

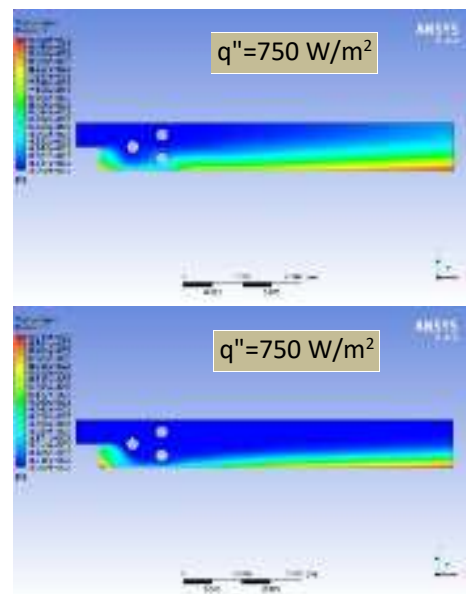

(c)

Fig. 7. Counters of (a) velocity (b) pressure and (c) temperature at selected Reynolds number and heat flux for case 3

The recirculating zones after the cylinders and on the upper and lower walls behind the second column of the cylinders is affected by increasing the distance between them. The pressure will be slightly affected by changing the distance between the cylinders. The temperature will be affected by the increasing the distance between cylinders, especially at low Reynolds number. The thermal boundary layer thickness will be higher with increasing the distance between cylinders.

The velocity profiles for case 1 and several Reynolds numbers are shown in Figure 8 for three streamwise locations $(x=0.01,0.03,0.05 \mathrm{~m}$ ) which mean before, between, and after the cylinders respectively. The zero value in the vertical axis represent the lower corner of the step where $(x=0)$. The flow zone below and above the cylinders will affect due to the presence of the cylinders, at $(x=$ $0.01 \mathrm{~m})$, the flow in the positive $(y)$ have higher velocity magnitude than the flow in the negative $(y)$ due to the effect of inlet velocity and the step edge. The flow zone begins to act as a jet between and after the cylinders. The effect of the cylinders is clear on the lower fluid flow zone between the cylinders, the flow velocity increase in this zone. The flow zone after the cylinders converted to three jet like velocity profile, while the velocity in the recirculating zone after each cylinder remain low. 


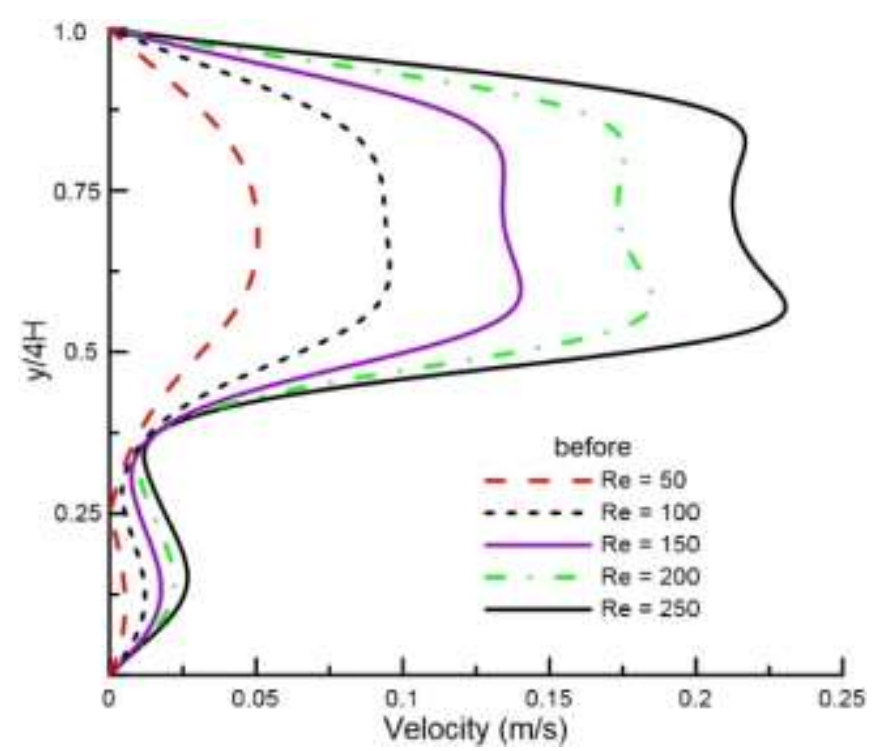

(a)

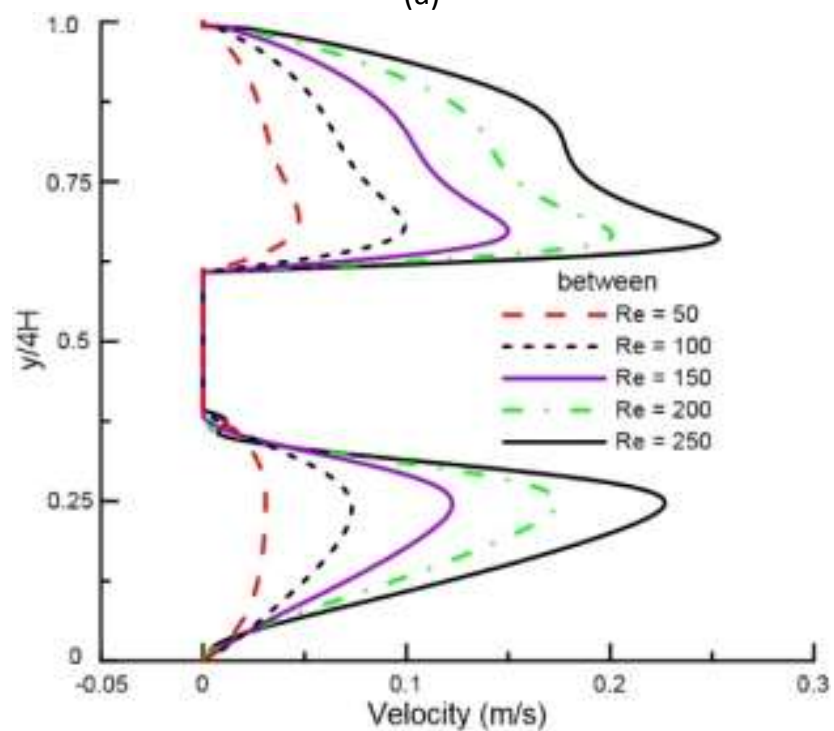

(b)

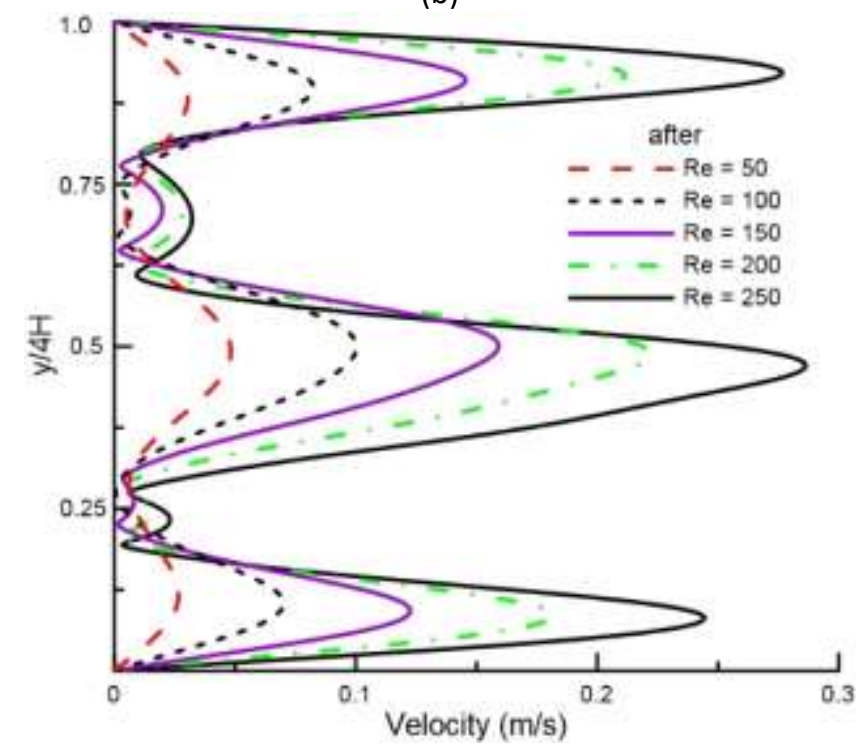

(c)

Fig. 8. Velocity profile at three streamwise locations, (a) $x=0.01 \mathrm{~m}$, (b) $x=0.03 \mathrm{~m}$, and (c) $x=0.05 \mathrm{~m}$ 
Figure 9 shows increasing the Nusselt number and heat transfer in the channel with increasing Reynolds number for all heat fluxes for case 1 . The effect of increasing the heat flux on the heat transfer is obvious, spatially at higher Reynolds number. The heat transfer increases by (6\%) at (Re $=50)$ and by $(13 \%)$ at $(\operatorname{Re}=250)$.

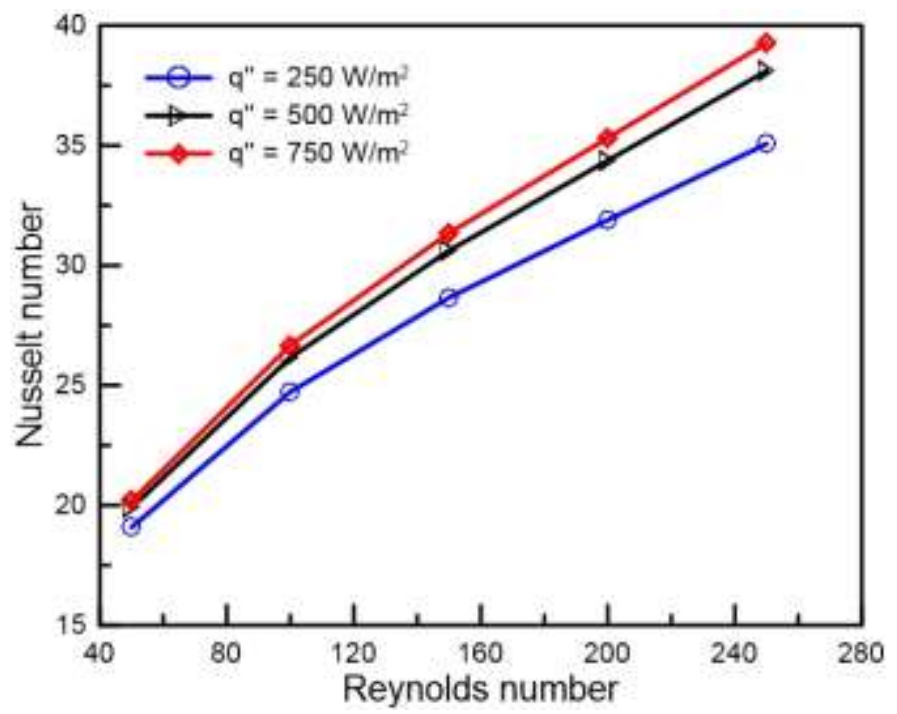

Fig. 9. The relation between heat transfer and fluid flow with different heat fluxes for case 1

In order to assess the role of obstacles on the heat transfer in the channel with step is further demonstrated if the Figure 10 for case 1 only. The Nusselt number relation with the streamwise distance in ( $x$ - direction) is shown for all Reynolds number and heat fluxes. At ( $R e=50)$, the Nusselt number increases with the direction from the lower corner of the step and reach its maximum value after the center point of the 2 nd column of the cylinders due to the presence of the cylinders, which compress the thermal boundary layer and leading to increase the heat transfer. The heat transfer will decay after that along the streamwise distance. Higher Reynolds number will increase the value of the maximum Nusselt number but its location remains unchanged.
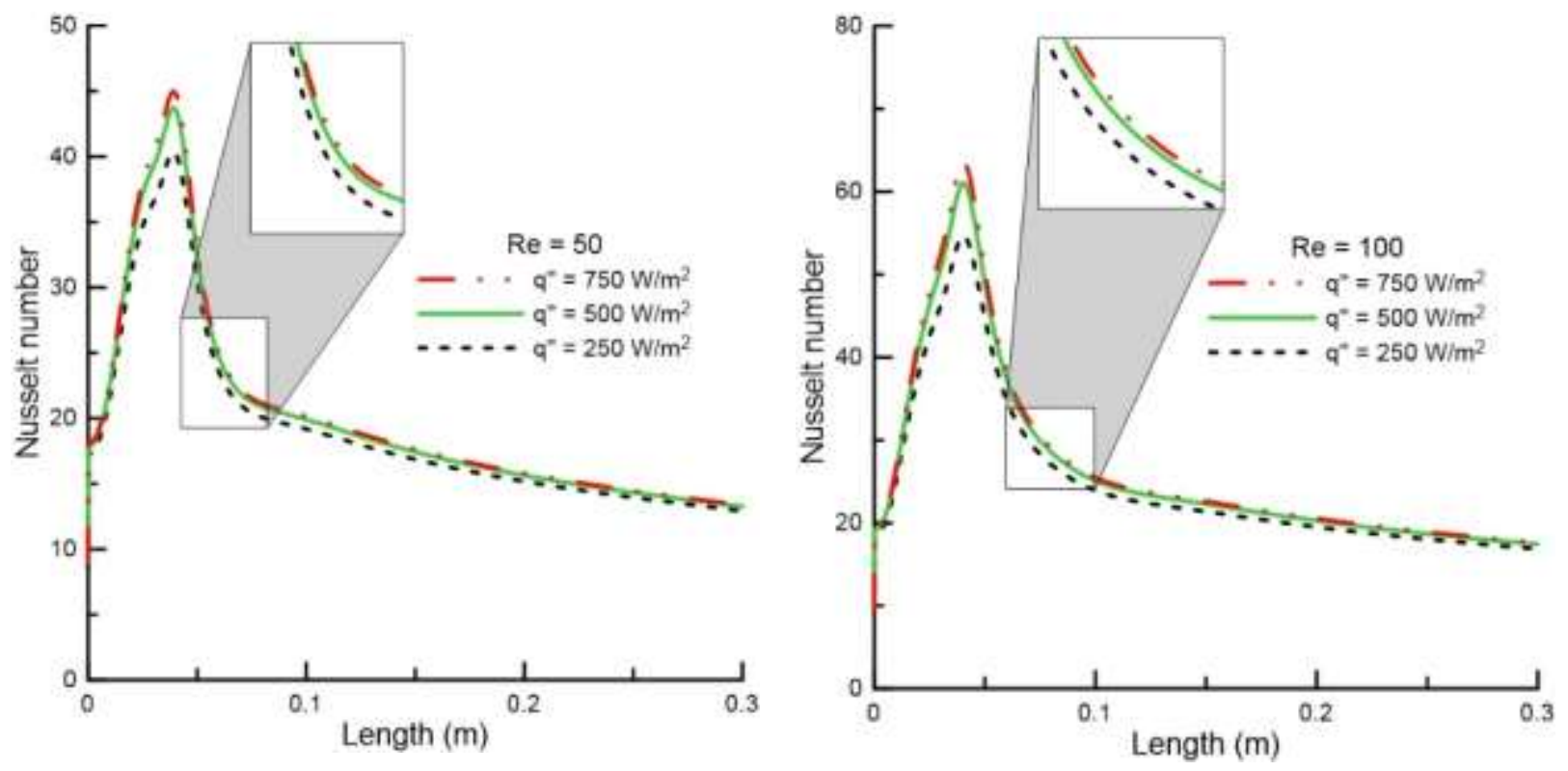


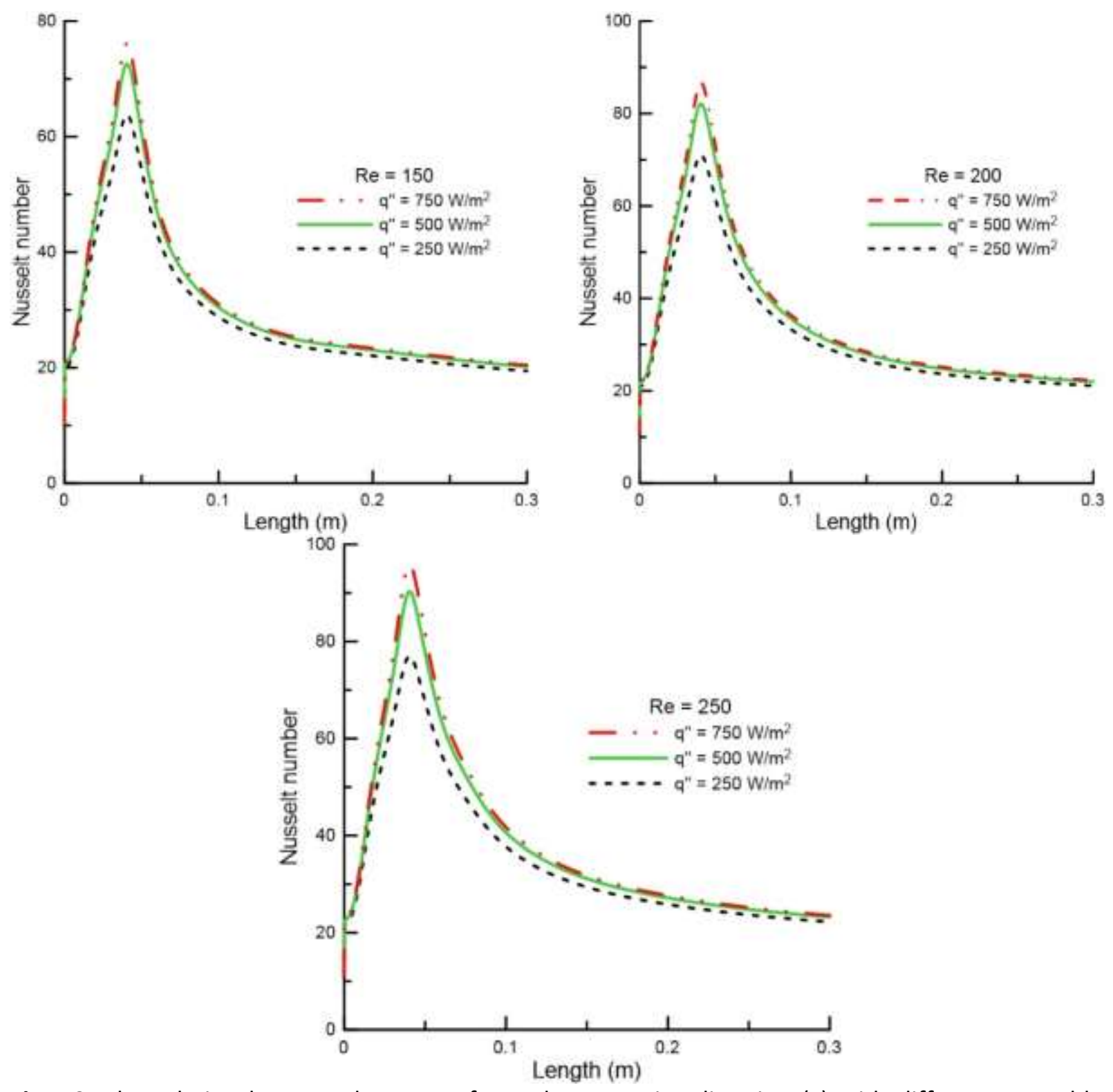

Fig. 10. The relation between heat transfer and streamwise direction $(x)$ with different Reynolds number and heat fluxes for case 1

\section{Conclusions}

In this work, a numerical study for the analysis of the heat transfer enhancement and laminar fluid flow characteristics of three cylinders in the backward facing step geometry is performed. The effects of Reynolds number ( $R e=50,100,150,200,250)$, heat fluxes $\left(q^{\prime \prime}=250,500,750 \mathrm{~W} / \mathrm{m}^{2}\right)$, and distance between cylinders $(2 \mathrm{H}, 3 \mathrm{H}, 4 \mathrm{H})$ on the heat transfer characteristics are studied for backward facing step flow. The following conclusions can be drawn:

i. The reattachment distance of the flow is reduced in the presence of cylinders.

ii. At low (Re), the thermal boundary layer will penetrate upward into the channel with increasing the distance between the cylinders.

iii. The velocity field is strongly affected by the cylinders, it is changed to jet like profile after them.

iv. The heat transfer is enhanced by $(6 \%)$ at $(\operatorname{Re}=50)$ when the heat flux increases by $(67 \%)$. Enhancement increases to $(13 \%)$ for $(\operatorname{Re}=250)$. 
v. The maximum Nusselt number occur after the center point of the 2 nd column. And its value improved when Reynolds number increase.

vi. The difference between maximum Nusselt number for different heat flux is increased from Eq. (5) to Eq. (17) when the Reynolds number increased from (50 to 250).

\section{References}

[1] Goldstein, R. J., V. L. Eriksen, R. M. Olson, and E. R. G. Eckert. "Laminar separation, reattachment, and transition of the flow over a downstream-facing step." Journal of Basic Engineering, Transactions of the ASME 92, no. 4 (1970): 732-739.

https://doi.org/10.1115/1.3425124

[2] Aung, W., and R. J. Goldstein. "Heat transfer in separated flow downstream of a rearward-facing step." Israel Journal of Technology 10, no. 1-2 (1972): 35-41.

[3] Aung, W. "An experimental study of laminar heat transfer downstream of backsteps." Journal of Heat Transfer 105, no. 4 (1983): 823-829. https://doi.org/10.1115/1.3245668

[4] Armaly, Bassem F., F. Durst, J. C. F. Pereira, and B. Schönung. "Experimental and theoretical investigation of backward-facing step flow." Journal of Fluid Mechanics 127 (1983): 473-496.

https://doi.org/10.1017/S0022112083002839

[5] Sparrow, Ephraim M., S. S. Kang, and Winston Chuck. "Relation between the points of flow reattachment and maximum heat transfer for regions of flow separation." International Journal of Heat and Mass Transfer 30, no. 7 (1987): 1237-1246. https://doi.org/10.1016/0017-9310(87)90157-8

[6] Ota, Terukazu. "A survey of heat transfer in separated and reattached flows." Applied Mechanics Reviews 53, no. 8 (2000): 219-235. https://doi.org/10.1115/1.3097351

[7] Iwai, Hiroshi, Kazuyoshi Nakabe, and Kenjiro Suzuki. "Flow and heat transfer characteristics of backward-facing step laminar flow in a rectangular duct." International Journal of Heat and Mass Transfer 43, no. 3 (2000): 457-471. https://doi.org/10.1016/S0017-9310(99)00140-4

[8] Selimefendigil, Fatih, and Hakan F. Öztop. "Identification of forced convection in pulsating flow at a backward facing step with a stationary cylinder subjected to nanofluid." International Communications in Heat and Mass Transfer 45 (2013): 111-121.

https://doi.org/10.1016/j.icheatmasstransfer.2013.04.016

[9] Heshmati, A., H. A. Mohammed, and A. N. Darus. "Mixed convection heat transfer of nanofluids over backward facing step having a slotted baffle." Applied Mathematics and Computation 240 (2014): 368-386. https://doi.org/10.1016/i.amc.2014.04.058

[10] Selimefendigil, Fatih, and Hakan F. Öztop. "Effect of a rotating cylinder in forced convection of ferrofluid over a backward facing step." International Journal of Heat and Mass Transfer 71 (2014): 142-148. https://doi.org/10.1016/j.ijheatmasstransfer.2013.12.042

[11] Selimefendigil, Fatih, and Hakan F. Öztop. "Numerical investigation and reduced order model of mixed convection at a backward facing step with a rotating cylinder subjected to nanofluid." Computers \& Fluids 109 (2015): 27-37. https://doi.org/10.1016/j.compfluid.2014.12.007

[12] Fathinia, F., and Ahmed Kadhim Hussein. "Effect of blockage shape on unsteady mixed convective nanofluid flow over backward facing step." CFD Letters 10, no. 1 (2018): 1-18.

[13] Hussain, Shafqat, Khalid Mehmood, Muhammad Sagheer, and Asifa Ashraf. "Mixed convective magnetonanofluid flow over a backward facing step and entropy generation using extended Darcy-Brinkman-Forchheimer model." Journal of Thermal Analysis and Calorimetry 138, no. 5 (2019): 3183-3203.

https://doi.org/10.1007/s10973-019-08347-w

[14] Mohammed, H., O. A. Alawi, and N. A. Che Sidik. "Mixed convective nanofluids flow in a channel having forwardfacing step with baffle." Journal of Advanced Research in Applied Mechanics 24 (2016): 1-21.

[15] Pozarlik, Artur Krzysztof, and Jacobus B. W. Kok. "Numerical simulation of a turbulent flow over a backward facing step with heated wall: effect of pulsating velocity and oscillating wall." Journal of Thermal Science and Engineering Applications 4, no. 4 (2012). https://doi.org/10.1115/1.4007278

[16] Selimefendigil, Fatih, and Hakan F. Öztop. "Numerical analysis of laminar pulsating flow at a backward facing step with an upper wall mounted adiabatic thin fin." Computers \& Fluids 88 (2013): 93-107. 
https://doi.org/10.1016/i.compfluid.2013.08.013

[17] Selimefendigil, Fatih, and Hakan F. Oztop. "Control of laminar pulsating flow and heat transfer in backward-facing step by using a square obstacle." Journal of Heat Transfer 136, no. 8 (2014).

https://doi.org/10.1115/1.4027344

[18] Suzuki, Hiroshi, Sigeo Kida, Takayuki Nakamae, and Kenjiro Suzuki. "Flow and heat transfer over a backward-facing step with a cylinder mounted near its top corner." International Journal of Heat and Fluid Flow 12, no. 4 (1991): 353-359.

https://doi.org/10.1016/0142-727X(91)90024-P

[19] Jue, Tswen-Chyuan, Horng-Wen Wu, and Sheng-Yuan Huang. "Heat Transferpredictions around Three Heated Cylinders Between Two Parallel Plates." Numerical Heat Transfer, Part A: Applications 40, no. 7 (2001): 715-733. https://doi.org/10.1080/104077801753289819

[20] Wu, Horng-Wen, Shiang-Wuu Perng, Sheng-Yuan Huang, and Tswen-Chyuan Jue. "Transient mixed convective heat transfer predictions around three heated cylinders in a horizontal channel." International Journal of Numerical Methods for Heat \& Fluid Flow 16, no. 6 (2006): 674-692.

https://doi.org/10.1108/09615530610679057

[21] Kumar, Ankit, and Amit K. Dhiman. "Effect of a circular cylinder on separated forced convection at a backwardfacing step." International Journal of Thermal Sciences 52 (2012): 176-185.

https://doi.org/10.1016/j.jithermalsci.2011.09.014

[22] Heshmati, Amirhossein, Hussein A. Mohammed, Mohammad Parsazadeh, Farshid Fathinia, Mazlan A. Wahid, Mohsin M. Sies, and Aminuddin Saat. "Effect of vertical baffle installation on forced convective heat transfer in channel having a backward facing step." In Applied Mechanics and Materials, vol. 388, pp. 169-175. Trans Tech Publications Ltd, 2013.

https://doi.org/10.4028/www.scientific.net/AMM.388.169

[23] Sarma, KarumanchiViswanatha, N. Sekarapandian, S. Vengadesan, and Y. V. S. S. Sanyasiraju. "Effect on heat transfer for laminar flow over Backward Facing Step with square cylinder placed inside using Higher Order Compact Scheme." International Journal of Computational Engineering Research (IJCER) 6, no. 1 (2016): 52-59.

[24] Togun, Hussein, Tuqa Abdulrazzaq, S. N. Kazi, A. Badarudin, M. K. A. Ariffin, and M. N. M. Zubir. "Numerical study of heat transfer and laminar flow over a backward facing step with and without obstacle." International Journal of Mechanical, Aerospace, Industrial and Mechatronics Engineering 8, no. 2 (2014): 363-367.

[25] Mehrez, Insaf, Ramla Gheith, Fethi Aloui, and Sassi Ben Nasrallah. "Numerical Analysis of Flow and Heat Transfer at a Backward-Facing Step With an Obstacle Based on Lattice Boltzmann Method." In ASME 2016 Fluids Engineering Division Summer Meeting collocated with the ASME 2016 Heat Transfer Summer Conference and the ASME 2016 14th International Conference on Nanochannels, Microchannels, and Minichannels. American Society of Mechanical Engineers Digital Collection, 2016.

[26] Tahseen, Tahseen Ahmad, M. Ishak, Khalaf Ibrahim Hamada, M. M. Rahman, and Ataalah Hussain Jassim. "Hybrid CFD-ANN Scheme for Air Flow and Heat Transfer Across In-Line Flat Tubes Array." Tikrit Journal of Engineering Sciences 25, no. 2 (2018): 59-67.

https://doi.org/10.25130/tjes.25.2.08

[27] Tahseen, Tahseen Ahmad, M. Ishak, and M. M. Rahman. "An overview on thermal and fluid flow characteristics in a plain plate finned and un-finned tube banks heat exchanger." Renewable and Sustainable Energy Reviews 43 (2015): 363-380. https://doi.org/10.1016/i.rser.2014.10.070

[28] Biswas, G., M. Breuer, and F. Durst. "Backward-facing step flows for various expansion ratios at low and moderate Reynolds numbers." Journal of Fluids Engineering 126, no. 3 (2004): 362-374.

https://doi.org/10.1115/1.1760532

[29] Choi, Hoi Hyun, and John Nguyen. "Numerical investigation of backward facing step flow over various step angles." Procedia Engineering 154 (2016): 420-425. https://doi.org/10.1016/j.proeng.2016.07.508

[30] Sayehvand, Habib-Olah, Sakene Mehrdad Yari, and Parsa Amir Basiri. "Numerical study of forced convection heat transfer over three cylinders in staggered arrangement immersed in porous media." Thermal Science 22, no. 1 Part B (2018): 467-475. https://doi.org/10.2298/TSCl150808249S

[31] Anguraj, A., and J. Palraj. "Numerical study of fluid flow and heat transfer in a backward facing step with a rotating cylinder." Malaya Journal of Matematik (MJM) 6, no. 2 (2018): 435-442. https://doi.org/10.26637/MJM0602/0022

[32] Freitas, C. J. "Perspective: selected benchmarks from commercial CFD codes." Journal of Fluids Engineering 117, no. 2 (1995): 208-218. 
https://doi.org/10.1115/1.2817132

[33] Inc., Ansys. "ANSYS Fluent Tutorial Guide, Release 18.0." ANSYS (2017).

[34] Chen, Lin, Keisuke Asai, Taku Nonomura, Guannan Xi, and Tianshu Liu. "A review of backward-facing step (BFS) flow mechanisms, heat transfer and control." Thermal Science and Engineering Progress 6 (2018): 194-216. https://doi.org/10.1016/j.tsep.2018.04.004 